\title{
Genotyping of Acantamoeba spp. from rhisophere in Hungary
}

\author{
ERIKA OROSZ ${ }^{1 *}$ and KATALIN POSTA ${ }^{2}$ \\ ${ }^{1}$ Department of Parasitology, National Public Health Center, Budapest, Hungary \\ ${ }^{2}$ Institute of Genetics, Microbiology and Biotechnology, Szent István University, Gödöllo, Hungary
}

\section{Acta Microbiologica et} Immunologica Hungarica

67 (2020) 3, 171-175

DOI: $10.1556 / 030.66 .2019 .041$

(c) 2019 The Author(s)

\section{ORIGINAL ARTICLE}

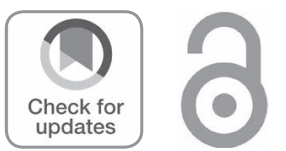

\footnotetext{
* Corresponding author:

Erika Orosz

Department of Parasitology, National Public Health Center, Albert Flórián út 2-6, H-1097 Budapest, Hungary Phone: +36 1 4761100/2231; E-mail: orosz.erika@nnk.gov.hu
}

Received: June 17, 2019 - Accepted: October 14, 2019

\begin{abstract}
The protista Acanthamoeba is a free-living amoeba existing in various environments. A number of species among protista are recognized as human pathogens, potentially causing Acanthamoeba keratitis (AK), granulomatous amoebic encephalitis (GAE), and chronic granulomatous lesions. In this study, 10 rhizosphere samples were collected from maize and alfalfa plants in experimental station at Institute of Genetics, Microbiology and Biotechnology, Szent István University. We detected Acanthamoeba based on the quantitative real-time PCR assay and sequence analysis of the 18S rRNA gene. All studied molecular biological methods are suitable for the detection of Acanthamoeba infection in humans. The quantitative real-time PCR-based methods are more sensitive, simple, and easy to perform; moreover, these are opening avenue to detect the effect of number of parasites on human disease. Acanthamoeba species were detected in five (5/10;50\%) samples. All Acanthamoeba strains belonged to T4 genotype, the main AK-related genotype worldwide. Our result confirmed Acanthamoeba strains in rhizosphere that should be considered as a potential health risk associated with human activities in the environment.
\end{abstract}

\section{KEYWORDS}

Acanthamoeba, rhizosphere isolates, genotypes

\section{INTRODUCTION}

Acanthamoeba is a genus of free-living amoebae widely distributed in various ecological environments [1-3]. The life cycle of Acanthamoeba species (sp.) consists of the active trophozoites and dormant cysts stages. Acanthamoeba trophozoites have a size between 20 and $40 \mu \mathrm{m}$, although this range can vary significantly among isolates of different species genotypes. Cysts are double-walled and range in size from 10 and $20 \mu \mathrm{m}$. This difference in size between the cyst and trophozoite involves a significant loss of cell volume mail due to cellular dehydrations. Acanthamoeba spp. are thermotolerant, which are resistant to extreme temperature, $\mathrm{pH}$ conditions, $\mathrm{UV}$, as well as to chlorine and other disinfectant media.

Most of the environmental studies are focusing on pathogenic Acanthamoeba sp. taxonomic and pathogenic markers, geographic distribution, ecology, and transmission dynamic [4-6]. Unlike obligate parasites, pathogenic Acanthamoeba spp. can complete their life cycle, environmental performance without having to enter the human or animal host [7,8]. The genus Acanthamoeba has been currently classified into 21 different genotypes, T1-T21, based on 18S rRNA nucleotide sequence [9, 10]. Some genera of Acanthamoeba cause different infections, which produce Acanthamoeba keratitis (AK), subacute or chronic granulomatous amoebic encephalitis, and skin infections. Human infections with these amoebae have been reported from all over the world [11]. The first cases that clearly established Acanthamoeba as causative agents of disease in humans have been reported in the early 1970s [12]. In many cases, AK infections occur after water exposure or a history of swimming in lakes, following contact with soil or plants, or while wearing contact lenses $[13,14]$. 
In general, Acanthamoeba are metabolically active and use a wide variety of bacteria, fungi, and organic matter as a food source [15].

Therefore, in this study, high microbial activities showing rhizosphere soil used for isolation protozoan organisms to test their occurrences are not in human host. Moreover, the isolated strains morphologically characterized by electron microscopy molecularly characterized based on the $18 \mathrm{~S}$ rRNA gene sequence and the robust phylogenetic analysis was also measured.

\section{MATERIALS AND METHODS}

\section{Samples collection}

Rhizosphere samples were collected from experimental station at Institute of Genetics, Microbiology and Biotechnology, Szent István University (longitude: 19²1'39.85", latitude: $\left.47^{\circ} 35^{\prime} 37^{\prime} 63^{\prime \prime}\right)$ in June 27,2018 . Rhizosphere samples were taken from the depth of $0-20 \mathrm{~cm}$. During the sampling period, altogether 10 samples from rhizosphere of maize and alfalfa plants samples were taken.

The sampling was performed, in which 10 samples were taken from rhizosphere of maize and alfalfa plants (notation: $\mathrm{K} 1 \_1, \mathrm{~K} 1 \_2, \mathrm{~K} 1 \_3$; K2_1, K2_2, K2_3; and L1_1, L1_2, L1_3, L2_1).

\section{Culture-confirmed detection method}

To concentrate Acanthamoeba spp., the samples were filtered, eluted, and centrifuged. Soil samples $(1 \mathrm{~g})$ collected from rhizosphere of maize and alfalfa plants were dissolved in $10 \mathrm{ml}$ of sterile physiological saline solution ( $0.85 \%)$ buffer and $500 \mu \mathrm{l}$ of each sample was inoculated onto PAGE agar 9-cm plates seeded with heat-killed Escherichia coli and incubated at $36^{\circ} \mathrm{C}[16]$.

\section{Microscopic detection}

Samples were examined under a microscope for 72-96 h at $400 \times$ with an inverted ZEISS microscope (Figure 1).

\section{Molecular analysis}

The Acanthamoeba species were isolated by dilution method. For this purpose, the samples of soil $(1 \mathrm{~g})$ were suspended in $10 \mathrm{ml}$ of sterile physiological saline solution $(0.85 \%)$. After preparation, the DNA extraction was treated with High Pure PCR Template Preparation Kit (Germany), according to the instructions of the manufacturer. If further processing was delayed, the isolates were stored at $4{ }^{\circ} \mathrm{C}$ for $24 \mathrm{~h}$ or at $-20{ }^{\circ} \mathrm{C}$ for a longer period. The DNA amplification was performed using genus-specific primers and genus-specific fluorescence resonance energy transfer (FRET) hybridization probes, previously described by Orosz et al. [17]. Each experiment included one reaction mixture without DNA as a negative control; positive control and each specimen were run in duplicate for real-time PCR assay in parallel. We have used serial dilutions of Acanthamoeba (GenBank accession number: KC434439) strain to determine the calibration curve that the liquid chromatography device could determine the additional samples parasite number in copy numbers.

PCR products were purified with PCR Clean up-M Kit (Viogene, Sunville, CA). The sequence of each amplicon was determined by cycle sequencing with primers for the $5^{\prime}$-NTR region and with primers with BigDye Terminator v3.1 Cycle Sequencing Kit (Applied Biosystems, Germany), according to the manufacturer's instruction. The electrophoresis was carried out on Applied Biosystems 3500 Genetic Analyzer (Applied Biosystems, Budapest, Hungary).

The $5^{\prime}$-NTR and VP1 gene sequences were subject to nucleotide-nucleotide BLAST analysis [18] using the online server at the National Center for Biotechnology Information (http://blast.ncbi.nlm.nih.gov/Blast).

The unknown sequences were aligned with known published sequences of the major genotypes using the alignment program MULTALIN (http://multalin.toulouse.inra.fr/ multalin) [19]. The genotypes of samples were determined based on this comparison.

The phylogenetic tree was constructed by the neighborjoining method of genetic distance calculated by the MEGA 6 (http://www.megasoftware.net) [20].

Genotype identification was carried out with a real-time FRET PCR assay based on sequence analysis of the 18S rRNA gene, and sensitivity and specificity were evaluated in comparison with traditional parasitological techniques.

Figure 1. Photomicrograph of Acanthamoeba trophozoites (A) and cysts (B) with $400 \times$ magnification. Photographer: Erika Orosz
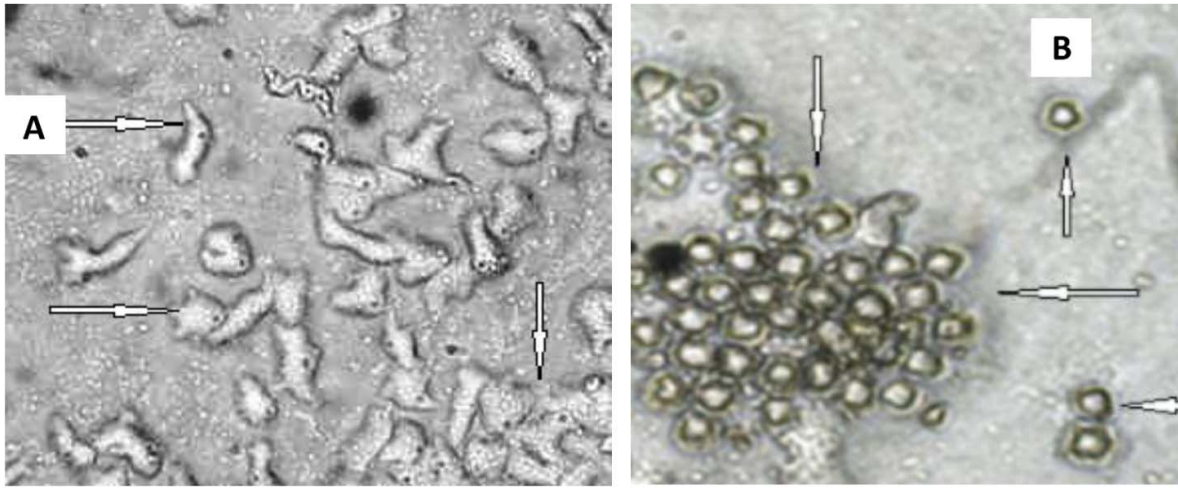


\section{RESULTS}

\section{Microscopic detection}

All investigated samples revealed Acanthamoeba were able to grow at $36{ }^{\circ} \mathrm{C}$, the approximate temperature of the human organism. Microscopically 5 out of the 10 samples were declared as Acanthamoeba positive (Medicago sativa L1_2, L1_3 and Zea mays - K1_2, K2_1, K2_3). Five rhizosphere samples (Medicago sativa - L1_1, L1_3 and Zea mays - K1_1, K1_3, K2_2) were microscopically negative. Further examination of the obtained results was conducted by FRET PCR.

\section{Molecular analysis}

This study reports successful PCR amplification for $5(5 / 10$; 50.0\%) positive cases. The samples of five Acanthamoeba positive samples, detected by PCR method, were sequenced to identify the species. Sequence analysis using a BLAST search indicated an identity of $>98 \%$ with Acanthamoeba $18 \mathrm{r}$ rRNA gene reference sequences. It was found that all obtained sequences of amoebae isolates from the cases belong to the different T4 genotypes Acanthamoeba spp. Neighbor-joining analysis inferred relationships between the PCR products isolated from rhizosphere samples reference strains obtained from NCBI GenBank, shown in Figure 2, respectively.

Figure 2. Phylogenetic relations of Acanthamoeba species PCR product sample L1_2, sample L1_3, sample K2_1, sample K2_1, sample K2_3, and reference strains from NCBI GenBank inferred by neighbor-joining analysis from pairwise comparisons (180-bp fragments)

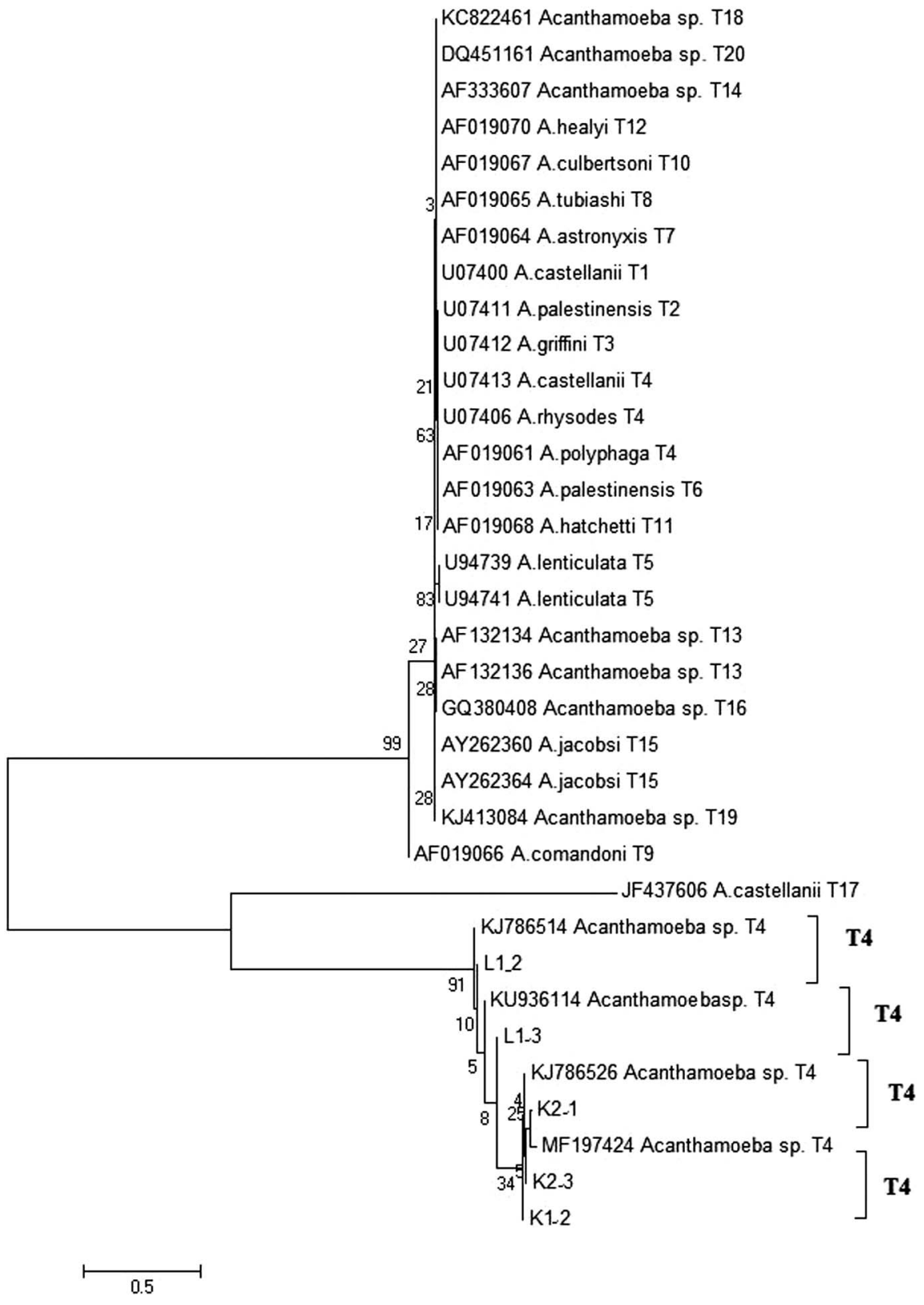




\section{DISCUSSION AND CONCLUSIONS}

Studies of Acanthamoeba have grown exponentially. To the best of our knowledge, this is the second study of occurrence of Acanthamoeba similar to T4 genotypes in rhizosphere samples from Hungary. These organisms have gained attention from the broad scientific community studying environmental biology, molecular biology, and biochemistry. Literature describes T4 genotype Acanthamoeba, as the most common in the environment. These results are consistent with previous findings indicating that $\mathrm{T} 4$ is worldwide predominant [21-24].

However, the correct understanding of the factors influencing the occurrence of the different species appears of great concern, as these amoebae are free-living organisms, and their potential capabilities to cause severe infections of the central nervous system, ocular keratitis, and other disorders are now ascertained worldwide.

All the isolates in this study exhibited morphological features of the genus Acanthamoeba confirmed by means of quantitative real-time PCR. Quantitative real-time PCR with FRET hybridization probes method is the most sensitive with a short turnaround time. It is possible even to estimate the parasite number in the samples with method. Therefore, only molecular methods allow reliable differentiation of the Acanthamoeba species. Based on rRNA gene sequences, the genus Acanthamoeba is divided into 21 different genotypes to date (T1-T21). Each genotype exhibits $5 \%$ or more sequence divergence between different genotypes. Five isolates were characterized as similar to genotype T4 due to their strict correspondence to the reference sequences of this genotype (GenBank accession number: KJ786514, KU936114, KJ786526, and MF197424). Sequence date indicate that the vast majority of them causes human infections. Contrary to data on Acanthamoeba infections in humans, little is known about infections in rhizosphere. It has been concluded that the rhizosphere isolates are most closely related to strains commonly isolated from human infections, especially AK [25-29].

In conclusion, our results confirm and support previous report on Acanthamoeba genotype free-living amoeba in rhizosphere soil. A homologous analysis of the 18S rRNA of five Acanthamoeba species isolated from rhizosphere of maize and alfalfa was identified into one genotype, namely T4. These genotypes were associated with AK or encephalitis; therefore, the presence of Acanthamoeba should be considered as potential health threat associated with human activity in soil.

Acknowledgements: This work was supported by Higher Education Institutional Excellence Program (NKFIH-11596/2019) awarded by the Ministry of Human Capacities within the framework of water-related researches of Szent István University.

Conflict of Interest: There is no conflict of interest. The corresponding author assures that there are no links with a company whose product is mentioned in the article or a company that distributes a competing product. The presentation of the topic is independent and the presentation of the content is product-neutral.

\section{REFERENCES}

1. Shatilovich, A., Shmakova, L., Gubin, S., Goodkov, A., Gilichinsky, D.: Viable protozoa in late Pleistocene and Holocene permafrost sediments. Dokl Biol Sci 401, 136-138 (2005).

2. Siddiqui, R., Khan, N. A.: Biology and pathogenesis of Acanthamoeba. Parasit Vectors 10, 6 (2012).

3. Reyes-Batlle, M., Zamora-Herrera, J., Vargas-Mesa, A., ValerónTejera, M. A., Wagner, C., Martín-Navarro, C. M., LópezArencibia, A., Sifaoui, I., Martínez-Carretero, E., Valladares, B., Piñero, J. E., Lorenzo-Morales, J.: Acanthamoeba genotypes T2, T4, and T11 in soil sources from El Hierro island, Canary Islands, Spain. Parasitol Res 115, 2953-2956 (2016).

4. Podlipaeva, J., Shmakova, L., Gilichinski, D., Goodkov, A.: Heat shock protein of hsp70 family revealed in some contemporary freshwater amoebae and in Acanthamoeba sp. from cysts isolated from permafrost samples. Tsitologiia 48, 691-694 (2006).

5. Nuprasert, W., Putaporntip, C., Pariyakanok, L., Jongwutiwes, S.: Identification of a novel t17 genotype of Acanthamoeba from environmental isolates and 10 genotype causing keratitis in Thailand. J Clin Microbial 48, 4636-4640 (2010).

6. Visvesvara, G. S., Hercules, M., Schuster, F. L.: Pathogenic and opportunistic free-living amoebae: Acanthamoeba spp., Balamuthia mandrillaris, Naegleria fowleri and Sappinia diploidea. FEMS Immunol Med Microbiol 50, 1-26 (2007).

7. Alves, D. S., Moraes, A. S., Nitz, N., de Oliveira, M. G., Hecht, M. M., Gurgel-Gonçalves, R., Cuba, C. A.: Occurrence and characterization of Acanthamoeba similar to genotypes T4, T5, and T2/T6 isolated from environmental sources in Brasília. Exp Parasitol 131, 239-244 (2012).

8. Karakavuk, M., Aykur, M., Şahar, E. A., Karakuş, M., Aldemir, D., Döndüren, Ö., Özdemir, H. G., Can, H., Gürüz, A. Y., Dağcl, H., Döşkaya, M.: First time identification of Acanthamoeba genotypes in the cornea samples of wild birds; Is Acanthamoeba keratitis making the predatory birds a target? Exp Parasitol 183, 137-142 (2017).

9. Montoya, A., Miró, G., Saugar, J. M., Fernández, B., Checa, R., Gálvez, R., Bailo, B., Marino, V., Piñero, J. E., Lorenzo-Morales, J., Fuentes, I.: Detection and molecular characterization of Acanthamoeba spp. in stray cats from Madrid, Spain. Exp Parasitol 188, 8-12 (2018).

10. Corsaro, D., Köhsler, M., Di Filippo, MM., Venditti, D., Monno, R., Di Cave, D., Berrilli, F., Walochnik, J.: Update on Acanthamoeba jacobsi genotype T15, including full-length $18 \mathrm{~S}$ rDNA molecular phylogeny. Parasitol Res 116, 1273-1284 (2017).

11. Khan, N. A., Jarroll, E. L., Paget, T. A.: Molecular and physiological differentiation between pathogenic and nonpathogenic Acanthamoeba. Curr Microbiol 45, 197-202 (2002).

12. Jones, D., Visvesvara, G., Robinson, N.: Acanthamoeba polyphaga keratitis and Acanthamoeba uveitis associated with fatal meningoencephalitis. Trans Ophthalmol Soc UK 95, 221-231 (1975).

13. Schroeder, J. M., Booton, G. C., Hay, J., Niszl, I. A., Seal, D. V., Markus, M. B., Fuerst, P. A., Byers, T. J.: Use of subgenic $18 \mathrm{~S}$ ribosomal DNA PCR and sequencing for genus and genotype identification of Acanthamoebae from humans with keratitis and from sewage sludge. J Clin Microbial 39, 1903-1911 (2001). 
14. Walochnik, J., Scheikl, U., Haller-Schober, E. M.: Twenty years of Acanthamoeba diagnostics in Austria. J Eukaryot Microbiol 62, 3-11 (2015).

15. Neelam, S., Niederkorn, J. Y.: Pathobiology and immunobiology of Acanthamoeba keratitis: Insights from animal models. Yale J Biol Med 90, 261-268 (2017).

16. Page, F. C.: A New Key to Freshwater and Soil Gymnamoebae. Freshwater Biological Association, Ambleside, Cumbria, 1988, $122 \mathrm{p}$.

17. Orosz, E., Farkas, Á., Ködöböcz, L., Becsák, P., Danka, J., Kucsera, I., Füleky, G.: Isolation of Acanthamoeba from the rhizosphere of maize and lucerne plants. Acta Microbiol Immunol Hung 60, 29-39 (2013).

18. Altschul, S. F., Gish, W., Miller, W., Myers, E. W., Lipman, D. J.: Basic local alignment search tool. J Mol Biol 215, 403-410 (1990).

19. Corpet, F.: Multiple sequence alignment with hierarchical clustering. Nucleic Acids Res 16, 10881-10890 (1988).

20. Tamura, K., Stecher, G., Peterson, D., Filipski, A., Kumar, S.: MEGA6: Molecular evolutionary genetics analysis version 6.0. Mol Biol Evol 30, 2725-2729 (2013).

21. Montalbano Di Filippo, M., Santoro, M., Lovreglio, P., Monno, R., Capolongo, C., Calia, C., Fumarola, L., D’Alfonso, R., Berrilli, F., Di Cave, D.: Isolation and molecular characterization of free-living amoebae from different water sources in Italy. Int J Environ Res Public Health 12, 3417-3427 (2015).

22. Üstüntürk-Onan, M., Walochnik, J.: Identification of freeliving amoebae isolated from tap water in Istanbul, Turkey. Exp Parasitol 195, 34-37 (2018).
23. Reyes-Batlle, M., Hernández-Piñero, I., Rizo-Liendo, A., López-Arencibia, A., Sifaoui, I., Bethencourt-Estrella, C. J., Chiboub, O., Valladares, B., Piñero, J. E., Lorenzo-Morales, J.: Isolation and molecular identification of free-living amoebae from dishcloths in Tenerife, Canary Islands, Spain. Parasitol Res 118, 927-933 (2019).

24. Orosz, E., Farkas, Á., Kucsera, I.: Laboratory diagnosis of Acanthamoeba keratitis in Hungary. Acta Microbiol Immunol Hung 63, 293-299 (2016).

25. Khan, N. A.: Acanthamoeba: Biology and increasing importance in human health. FEMS Microbiol Rev 30, 564-595 (2006).

26. Corsaro, D., Walochnik, J., Köhsler, M., Rott, M. B.: Acanthamoeba misidentification and multiple labels: Redefining genotypes T16, T19, and T20 and proposal for Acanthamoeba micheli sp. nov. (genotype T19). Parasitol Res 114, 2481-2490 (2015).

27. Orosz, E., Szentmáry, N., Kiss, H. J., Farkas, Á., Kucsera, I., Nagy, Z. Z.: First report of Acanthamoeba genotype T8 human keratitis. Acta Microbiol Immunol Hung 65, 73-79 (2018).

28. Gyenes, A., Orosz, E., Sándor, G. L., Fries, F. N., Seitz, B., Nagy, Z. Z., Szentmáry, N.: Early diagnosis and successful medical treatment of Acanthamoeba keratitis. Klin Monbl Augenheilkd 235, 1407-1410 (2018).

29. Orosz, E., Kriskó, D., Shi, L., Sándor, G., Kiss, H. J., Seitz, B., Nagy, Z. Z., Szentmáry, N.: Clinical course of Acanthamoeba keratitis isolates T4 and T8 in Hungary. Acta Microbiol Immunol Hung 66, 289-300 (2019).

Open Access statement. This is an open-access article distributed under the terms of the Creative Commons Attribution 4.0 International License (https://creativecommons.org/licenses/by/4.0/), which permits unrestricted use, distribution, and reproduction in any medium, provided the original author and source are credited, a link to the CC License is provided, and changes - if any - are indicated. (SID_1) 